\title{
Erinnerung an den Psychoanalytiker, Schriftsteller und anarchistischen Weltbürger Paul Parin (20.9.1916-18.5.2009)
}

\author{
Roland Kaufhold (Köln)
}

«Ich hab` mich schon seit 1934 auf die Chirurgie gestürzt, weil ich wusste, es kommt ein Weltkrieg». Eine für Paul Parin in ihrer Präzision und Nüchternheit typische Bemerkung bzgl. der Motive seiner ersten Berufswahl: Medizin. Gegen die Nationalsozialisten. Er machte sie 1992 bei einer Lesung in Köln. Am 18.5.2009, ist der streitbare, liebenswerte Schweizer Schriftsteller und Psychoanalytiker Paul Parin 92-jährig in seiner Heimatstadt Zürich verstorben, wo er seit 1938, mit Unterbrechungen, gelebt hat. Er war für mich ein Vorbild. Kein Autor hat mich mit seinen tiefgründigen, erzählenden Büchern und Essays so tief bewegt, so angeregt wie Paul Parin.

Erstmals gelesen habe ich ihn 1981 im Philosophieunterricht eines Gymnasiums, bei einem «progressiven» Lehrer, kurz vor meinem Abitur. Es war die Zeit der «Züricher Jugendunruhen». «Befreit Grönland vom Packeis» stand an Züricher Häusern. Der seinerzeit 65-jährige, aus einem großbürgerlichen, privilegierten jüdischen Familienhaus stammende Paul Parin bemühte sich, die aufbegehrende Jugend solidarisch zu unterstützen - mit seinen Mitteln: Er publizierte psychoanalytische Studien: «Warum die Psychoanalytiker so ungern zu brennenden Zeitproblemen Stellung nehmen», «Befreit Grönland vom Packeis», «Der Knopf an der Uniform des Genossen», «Zunehmende Intoleranz in der Bundesrepublik»: typische Essayüberschriften für sein seinerzeitiges publizistisches Engagement.

Paul Parin wuchs in Slowenien als Sohn eines Großgrundbesitzers auf. Sein Elternhaus war «multikulturell», assimiliert jüdisch, anregungsreich - aber auch einsam. Der junge Paul fand auf dem elterlichen Anwesen kaum gleichaltrige Freunde. Und er musste sehr früh schwere Belastungen überstehen. Wegen einer angeborenen Missbildung seines Hüftgelenkes war er als Kind für mehrere Monate von Kopf bis Fuß eingegipst - und hatte doch zugleich eine liebevolle, einfühlsame Mutter. Seine Beobachtungsgabe wurde so früh geweckt. Paul besuchte bis zu seinem 17. Lebensjahr keine Schule, sondern erhielt nur Hausunterricht. Er las viel, sehr viel, baute eine eigene Bücherei auf, machte aber auch Ausflüge in die Natur. In einigen seiner autobiographisch getönten literarischen Werken, so in «Jahre in Slowenien» (1981), «Karakul» (1993), «Eine Sonnenuhr für beide Hemisphären» 
(1995) und «Der Traum von Segou» (2001) hat er hiervon in sehr persönlicher Weise erzählt. Mit 17 Jahren besuchte er in Graz erstmals ein Gymnasium, um einen offiziellen Schulabschluss zu erlangen. Für den Juden Paul Parin war dies ein herausforderndes, seinen Widerstandsgeist weckendes Erlebnis: Es war, wie er es selbst formulierte, eine «Nazischule», der größte Teil seiner Mitschüler wie auch seiner Lehrer sympathisierten mit den Nationalsozialisten. Paul Parin wusste, was dies für ihn bedeutete. Er studierte in Graz, Zagreb und Zürich Medizin, wo er auch promovierte. Und doch interessierte er sich bereits als Jugendlicher für die Psychoanalyse, las die Schriften Freuds: «Freud war einer der bahnbrechenden Kritiker unserer Zivilisation. In unserer Jugend, der Zeit der faschistischen Bewegung und neu entfesselter schrecklicher und grausamer Kriege, schien es uns nötig und dringlich, die Zivilisationskritik Freuds weiterzutreiben», erinnerte er sich 1998 in einem in der NZZ publizierten Essay.

Im Oktober 1944 verließ der 27-jährige aus Protest gegen die offizielle, tolerierende Haltung der Schweizer Regierung gegenüber den Nationalsozialisten seine Regierung stempelte ein «J» in die Pässe der verzweifelten, Zuflucht suchenden jüdischen Flüchtlinge-Zürich und brach gemeinsam mit sechs Schweizer Kollegen der Ärzte- und Sanitätshilfe - hierunter auch seine spätere Ehefrau Goldy ParinMatthèy - unter abenteuerlichen Umständen zu den jugoslawischen Partisanen auf. Frei von trügerischen Illusionen beteiligten sie sich als anarchistisch-sozialistische «Brüdergemeinde» mit ihrer chirurgischen Mission im antifaschistischen Kampf:

«Wir waren diszipliniert, wenn wir selber es für richtig hielten; jeder Befehl verletzte unsere Würde. Wir fühlten uns als Weltbürger, solidarisch mit allen, die unterdrückt und ausgebeutet werden. Deshalb war für uns jede Heimat zu eng und die Verpflichtung auf eine Linie eine Fessel» erinnerte sich Paul Parin 1991 in «Es ist Krieg und wir gehen hin» an seine damaligen Motive. Sein literarisches Erinnerungsbuch an seine Zeit bei den jugoslawischen Partisanen fand Anfang der 1980er Jahre eine breite Resonanz. Auf Vorschlag von Christa Wolf wurde es mit dem Erich Fried Literaturpreis ausgezeichnet.

Von 1946 bis 1952 absolvierte Paul Parin in Zürich eine Ausbildung in Neurologie und Psychoanalyse und war 1958 Mitbegründer des Psychoanalytischen Seminars Zürich (PSZ), welches er gemeinsam mit seinem Freund und Praxiskollegen Fritz Morgenthaler nachdrücklich prägte.

Die Parins suchte immer wieder Freiräume, neue Erfahrungen, waren von einem unstillbaren Wissensdurst inspiriert. Von 1954 bis 1971 unternahmen sie sechs selbst finanzierte Forschungsreisen nach Westafrika, um mit Hilfe der psy- 
choanalytischen Gesprächstechnik das Seelenleben westafrikanischer Völker zu untersuchen. Durch seine hieraus erwachsenen, inzwischen legendären Studien über die Dogon - «DieWeißen denken zuviel» (1963) und «Fürchte Deinen Nächsten wie Dich selbst» (1971) - wurde er zum Mitbegründer der Ethnopsychoanalyse. Bereits in diesen frühen, bis heute immer wieder neu aufgelegten Werken war der für Parins Gesamtwerk zutiefst prägende Übergang zwischen wissenschaftlicher Analyse und literarischer Erzählung deutlich erkennbar. Natürlich war Paul Parin sehr bewusst, dass seine wissenschaftliche Grenzübertretung auch heftigen Widerspruch, Widerstand unter Kollegen auslösen würde. In seinem 1993 verfassten Vorwort zur 4. Auflage von «Die Weißen denken zuviel» erinnerte sich Parin:

«Die Voraussetzung für die Verbreitung des Buches war, dass wir unseren wissenschaftlichen Bericht so schreiben wollten, dass ihn Leser ohne psychoanalytische Kenntnisse verstehen könnten. Denn wir sahen voraus, dass unsere Fachkollegen nicht eben gerne lesen würden, wie wir ihren - und unseren - bequemen Lehnstuhl hinter der Couch verlassen und gegen einen flachen Stein im Schatten eines Brotfruchtbaumes oder in einer Felshöhle eingetauscht haben.» (Parin 2006, S. I)

1985 folgt mit seiner Erzählsammlung «Zu viele Teufel im Land» sein langer, schmerzhafter Abschied von Afrika. Diese faszinierende, erregende Essaysammlung ist von einem Gestus der Unerschrockenheit, der Neugierde, der emotionalen Offenheit geprägt, dem sich der aufgeschlossene Leser nicht zu entziehen vermag.

In den 1970er und 80er Jahren publizierte Paul Parin, zum Teil gemeinsam mit Goldy Parin-Matthèy, zahlreiche psychoanalytisch-kulturkritische Studien, versammelt in den Sammelbänden «DerWiderspruch im Subjekt» (1978) und «Subjekt im Widerspruch» (1986). Wo immer möglich und nötig mischte er sich fortan in den öffentlichen Diskurs ein, belebte diesen durch seinen unbestechlichen, analytisch geschärften Blick auf gesellschaftliche Gewaltverhältnisse, sowie mittels seiner beeindruckenden Sprachkraft. «Das Politische ist immer auch persönlich», was gleichermaßen auch umgekehrt gilt, verdeutlichte Parin immer wieder - sehr zum Unwillen vieler seiner konservativen Berufskollegen, die nach der schwierigen gesellschaftlichen Etablierung der Psychoanalyse gar zu gerne das kulturkritische Erbe Freuds loszuwerden versuchten. Ganz im Sinne der aufklärerischen und kulturrevolutionären Tradition der Freudschen Psychoanalyse insistierte Paul Parin: «Die Vergangenheit versinkt, und Geschichtslosigkeit droht sich einzustellen, wo immer es Herrschaft und Beherrschte gibt. Ohne eine Kultur, die ihre Kritik gegen die Machtverhältnisse richtet, ist kein Fortschritt möglich». Seine Position als 
kritischer Sozialist und «moralischer Anarchist» (Christa Wolf) brachte er mit den Worten Andrè Bretons zum Ausdruck: «Mit dieserWelt gibt es keine Verständigung. Wir gehören ihr nur in dem Maße an, als wir uns gegen sie auflehnen».

1980 schloss Paul Parin aus Altersgründen seine psychoanalytische Praxis. Im gleichen Jahr erschien mit «Untrügliche Zeichen von Veränderung: Jahre in Slowenien» sein literarisches Erstlingswerk, angefüllt mit Erinnerungen an seine Kindheit in dem von ihm geliebten Slowenien sowie an seine aufrührende Zeit bei den jugoslawischen Partisanen. Der Erzählband erhielt gleich einen Literaturpreis. 1990 folgte der kulturkritische Band «Noch ein Leben», 1992 sein Jugoslawienbuch «Es ist Krieg und wir gehen hin». 1993 und 1995 folgten seine Erzählsammlungen «Karakul» und «Eine Sonnenuhr für beide Hemisphären». Nach dem Tode seiner Ehefrau Goldy im Jahr 1997 schien Paul Parin kurzzeitig zu resignieren. Die Trauer schien übermächtig. Seine Zuneigung zu Freunden gab ihm wieder Lebensmut. Er veröffentlichte literarische Erzählungen, die er als einen Epilog zu ihrem langen gemeinsamen Leben verstand. Er vermochte wieder zu schreiben, zu erzählen, sich zu erinnern. Der Versuchung zum Freitod gab er aus Liebe zu Freunden nicht nach. 2001 erschien mit «Der Traum von Segou» eine Sammlung von Erzählungen, 2003 der erregende, verstörende Band «Die Leidenschaft des Jägers», 2005 «Das Katzenkonzil» und 2006 - Paul Parin war zu diesem Zeitpunkt nahezu erblindet seine Aufsatzsammlung «Lesereise 1955-2005». Nun wurde Paul Parin geradezu überhäuft mit wissenschaftlichen und literarischen Preisen. Vor zwei Jahren feierte das Psychoanalytische Seminar Zürich anlässlich seines 90. Geburtstages noch einmal in einer großen wissenschaftlichen Tagung das inspirierende Lebenswerk ihres intellektuellen Mentors und menschlichen Vorbildes; Emilio Modena publizierte diese interdisziplinären Vorträge in dem Band «Leidenschaften. Paul Parin zum 90. Geburtstag».

Als Grundmotiv für seine außergewöhnlich produktives wissenschaftlichliterarisches Engagement hat Paul Parin seinen Forschungsdrang, seine Sehnsucht nach Abenteuern und seinen ungebrochenen Humor und Optimismus benannt. In seiner Dankesrede zur Verleihung des Erich Fried Preises bemerkt er 1992: «Wenn mir die Ereignisse auf den Leib rücken, kann ich keine Geschichten mehr erzählen. (...) Die Versuchung, mich ganz in die Lesewelt zurückzuziehen ist da. Warum schweige ich nicht endlich und verzichte darauf zu schreiben? Weil ich gerne schreibe und weil ich Christa Wolf zustimme, die geschrieben hat: «Wer zu verzichten angefangen hat, ist auf Ungerechtigkeit festgelegt.»» 
Paul Parin war mir stets ein ferner und doch naher Freund. Ich habe für ihn ein Gefühl einer sehr tiefen Zuneigung empfunden. Ich werde diesen skeptischen Menschenfreund und großartigen Erzähler sehr vermissen. 